\title{
Secondary Infections in Patients with COVID-19
} Pneumonia Treated with Tocilizumab Compared to Those Not Treated with Tocilizumab:

\section{A Retrospective Study at a Tertiary Hospital in Kenya}

\author{
Reena Shah $\mathbb{D}^{1}$, Jasmit Shah', Jaimini Gohil ${ }^{2}$, Gunturu Revathi ${ }^{3}$, Salim Surani ${ }^{4}$ \\ 'Department of Internal Medicine, The Aga Khan University, Nairobi, Kenya; ${ }^{2}$ Department of Pharmacy and Therapeutics, The Aga Khan University, \\ Nairobi, Kenya; ${ }^{3}$ Department of Pathology, The Aga Khan University, Nairobi, Kenya; ${ }^{4}$ Department of Pulmonology \& Internal Medicine, Texas A\&M \\ University, Corpus Christi, Texas, USA \\ Correspondence: Reena Shah, Tel +254735338003, Email reena.shah@aku.edu
}

\begin{abstract}
Introduction: From the first case of SARS-Co-2 in Wuhan, China, to the virus being declared as a pandemic in March 2020, the world has witnessed morbidity and mortality on a global scale. Scientists have worked at a record pace to deliver a vaccine for the prevention of this deadly disease. Tocilizumab, an interleukin-6 (IL-6) blocker, received an emergency use authorization (EUA) by the Federal Drug Agency (FDA) in June 2021.
\end{abstract}

Methods: This retrospective observational cohort study was conducted at the Aga Khan University Hospital, Nairobi, from March 8, 2020, to December 31, 2020. All patients with PCR confirmed COVID-19 pneumonia were included. Data were obtained from the medical records, and the admission registry was used to identify the patients, and both their electronic and paper-based files were retrieved from the medical records. Patient demographic data, medical history, baseline comorbidities, clinical characteristics, and outcome data were collected to study the infectious complications of Tocilizumab in patients affected by COVID-19 pneumonia.

Results: A total of 913 patients who were diagnosed with COVID-19 were included. The overall superinfection infection rate among the COVID-19 patients was $6 \%$. Superinfection in patients who received the Tocilizumab was $17.2 \%$ and in the non-Tocilizumab group was $4.8 \%$. The superinfection rate among severe and critically ill patients was even higher at $41.8 \%$ and $69.9 \%$ (Tocilizumab group) and $2.1 \%$ and $11.8 \%$ (non-Tocilizumab group), respectively $(\mathrm{p}<0.001)$. There was no difference in mortality observed between the groups $(\mathrm{p}=0.846)$. Infection among HIV co-infection was very low at $2.3 \%$.

Conclusion: Contrary to some studies, a higher rate of infection was observed among the Tocilizumab group, and no difference in mortality was observed between Tocilizumab and the non-Tocilizumab group. Infection among patients with HIV remains low in this susceptible population.

Keywords: COVID-19, SARS-CoV-2, EMPACTA, RECOVERY, Tocilizumab, IL-6, REMDATA, CONVACTA

\section{Introduction}

In December 2019, the first case of SARS-CoV2 was discovered in Wuhan, China, linked to an outbreak in the seafood market. ${ }^{1}$ It was later named COVID-19. Within months, the virus rapidly spread to several countries, and by March 11, 2020, it was labeled a pandemic by the World Health Organization (WHO). ${ }^{2}$ As of December 18, 2021, approximately 281 million people globally have been infected, with approximately 5.4 million deaths resulting from the virus. ${ }^{3}$ These numbers may be the tip of the iceberg, as most developing countries have poor data collection and public health reporting systems, especially within rural communities. 
Numerous trials have yielded controversial results, and multiple trials are still in process. So far, treatment options remain limited, with steroids in the forefront, followed by Tocilizumab or Baricitinib in COVID-19 patients with cytokine storm.

Tocilizumab is a monoclonal antibody with activity against the interleukin-6 (IL-6) receptors. It has been approved for the treatment of Rheumatoid arthritis, Systemic Juvenile Idiopathic Arthritis, life-threatening cytokine release syndrome, Giant Cell Arteritis, most recently received emergency use authorization for COVID-19. ${ }^{4-9}$ IL-6 is produced by various cells in response to inflammation, infection, trauma, or immunological attack. Tocilizumab is a monoclonal antibody that competitively inhibits the binding of IL- 6 to both membrane and soluble IL-6 receptors. ${ }^{10,11}$

Elevated levels in IL-6 have been observed in patients with COVID-19. ${ }^{12}$ Several small studies, both cohort and retrospective studies, have demonstrated the beneficial effects of using Tocilizumab. ${ }^{13-15}$ The decision of the Federal Drug Administration (FDA) for emergency use approval of Tocilizumab in combination with steroids in patients who require oxygen or invasive and non-invasive life support came from the data supported by the RECOVERY trial, CONVACTA Trial, EMPACTA trial, and the REMDACTA trial. ${ }^{11,15-17}$

Treatment with an IL-6 blocker is associated with a higher risk of infections. ${ }^{18}$ It is important to note that late-onset infection has been more commonly seen in patients who have used Tocilizumab when compared to the control group. ${ }^{19-22}$

Kenya is Tuberculosis (TB) endemic country with higher burdens of TB in urban settings (760 per 100,000) compared to rural settings (453 per 100,000 population). There is also a higher TB incidence among the elderly (65+ years). Kenya is also HIV endemic, with a prevalence rate of $4.9 \%$. Due to Kenya's status as a high burden country for both TB and HIV, there have been concerns that further immunosuppressing these patients with Tocilizumab may increase the number of TB and make way for opportunistic infections in these patients. ${ }^{23}$

Both WHO and NIH have endorsed Tocilizumab to treat cytokine storm crisis among patients with COVID-19. However, the data regarding the infectious complications related to the use of Tocilizumab is limited, especially in developing countries where there is a high prevalence of infectious and HIV diseases. We undertook the retrospective chart review study to look at the rate of superinfection among patients treated with the Tocilizumab and a nonTocilizumab group of the patients at a tertiary hospital in Kenya to address this issue.

\section{Methods}

A retrospective observational cohort study was conducted involving patients admitted for COVID-19 and bacterial or fungal coinfection/superinfection between March 8 and December 31, 2020. The study was conducted at the Aga Khan University Hospital, Nairobi (AKUHN), a 258-bed, private, not-for-profit, tertiary-level teaching and referral hospital.

All COVID-19 patients (children and adults: age 0 and above) with the confirmed diagnosis were enrolled based on positive real-time reverse transcription-polymerase chain reaction (RT-PCR) assays for SARS-CoV-2 from a nasopharyngeal swab. Lower respiratory samples were obtained if the nasopharyngeal swab was negative and if there was a high clinical index of suspicion. Patients discharged from the emergency department were excluded. All comorbidities were included. Including TB and HIV as we are a TB endemic country with a high national HIV prevalence. In the initial months of the pandemic, it was mandated by the Ministry of Health, Kenya, to isolate all patients in health facilities for management and care due to the rising number of COVID-19 cases. This was later changed to admit only those who required supplemental oxygen and presented with comorbidities. Therefore, the severity of disease in hospitalized patients evolved with the pandemic, with patients ranging from asymptomatic to severe in the initial months, to only severe/critical and those with co-morbidities in the later months.

Ethical approval for this study was obtained from the Institutional Ethics Review Committee at AKUHN. A waiver for informed consent was obtained as it was a retrospective study. All related procedures were followed in accordance with the Declaration of Helsinki. No patient identifiers were used, and data were abstracted from the medical chart records into the REDCap platform. 


\section{Laboratory Procedures}

SARS-CoV-2 infection was confirmed by real-time reverse transcriptase PCR (RT- $\neg$ PCR) assay (QuantStudio5- Applied Biosystems Thermo Fisher Scientific and MiC PCR from Bimolecular Systems) from nasopharyngeal swabs (Thermo Fisher Scientific) and viral transport media (CAPRICORN Scientific).

The microbiology laboratory at AKUHN is an accredited laboratory by the College of American Pathologists (CAP). The lab has consistently maintained external QC and proficiency testing scoring between $90-100 \%$.

Blood cultures were performed using a fully automated BD Bactec FX 40 system using BD Bactec plus aerobic and anaerobic media, which fully support the yeast growth from blood. All culture and susceptibility tests were performed using standard microbiology procedures. ${ }^{24-26}$

All clinically significant bacterial and yeast isolates were identified using Vitek 260 (bioMerieux Inc). The Vitek 260 system uses a fluorogenic methodology for organism identification and a turbidimetric method for susceptibility testing. Supplemental Disk diffusion and E tests were also used wherever applicable depending on the drug and pathogen combination (VITEK YST ID Card - Reference number 21343, VITEK2 Antifungal AST card -YS 08 Ref. 420739).

Vitek AST cards use CLSI breakpoints for the interpretation of antimicrobial and antifungal susceptibilities. ${ }^{25,26}$

\section{Definitions}

Diagnosis of a significant infection was based on the clinical presentation, the isolation of an etiological agent, and the assessment of the group of clinicians responsible for the patient. Bacteremia/fungemia was defined as the isolation of a pathogen in one or more blood cultures. For microorganisms of the cutaneous flora, its growth was assessed in two or more blood cultures extracted by different routes.

Coagulase-negative staphylococci were usually considered contaminants in blood culture unless repeatedly isolated from multiple blood cultures, or patients had the clinical background to consider them pathogens, eg, endocarditis, presence of prostheses, etc.

For catheter-associated bacteremia $(\mathrm{CAB})$, isolation of the same pathogen from blood and the catheter tip $(>15$ colonies on sheep blood agar plate) was considered significant, as well as pathogens from blood samples obtained in parallel or in two blood cultures extracted simultaneously from the catheter and by venipuncture. Respiratory infection (RI) was considered if there was significant isolation of a potentially pathogenic microorganism in bronchoalveolar lavage (BAL), in a bronchial aspirate (BAS), or in a sputum sample with an acceptable Q score $(>+1)$.

Urinary tract infection (UTI) was defined as isolation of a uropathogen, significant colony count with or without pyuria in a patient's urine sample with signs and/or symptoms of UTI. The diagnosis of skin and soft tissue infection (IPPB) was based on the direct Gram stain (PMN and presence of bacteria or fungi) culture isolation of a significant pathogen from a standard clinical sample.

\section{Intervention}

Tocilizumab was included in our internal institutional protocol for the treatment of COVID-19, specifically for use in patients with progressive clinical deterioration, increasing oxygen requirements, and elevated inflammatory markers at the discretion of the treating team and infectious diseases consultation service. Our protocol recommended a dose of $8 \mathrm{mg} / \mathrm{kg}$ Tocilizumab administered intravenously with the potential for redosing based on clinical response (eg, oxygenation status, hemodynamic stability, inflammatory marker response). Tocilizumab was not used in patients with deranged liver function test (LFT) with AST and ALT five-time upper limit of normal detected within 24 hours of screening. Patients with significant cytopenia or documented ongoing infection were also excluded. Similarly, patients enrolled in any other clinical trials were not eligible to receive Tocilizumab.

\section{Data Collection}

Data were collected by a research assistant from the medical records department using manual and electronic health records for all patients admitted with a diagnosis of critical COVID-19 prior to the study period. The data were extracted and entered into a REDCap $\odot$ database. ${ }^{27}$ Variables were grouped into demographic data, comorbidities such as diabetes, 
hypertension, heart disease, HIV status, COPD, renal disease, cancer and rheumatology disorders, risk factors such as COVID-19 severity, number, and type of infection, microbiological data, diagnostic imaging tests, antibiotic treatment (empirical and directed), and evolution during hospital admission. The patients were grouped into two categories according to their admission to the ICU. Patients with microbiological isolates considered contaminants were excluded from the study. After data collection and coding, the data collected was exported to SPSS for analysis (IBM Statistical Package for the Social Sciences version 20.00).

\section{Statistical Analysis}

Categorical data were summarized as frequencies and percentages, whereas continuous data were summarized as means and standard deviations (SD). The normality of the data was analyzed using the Shapiro Wilk test for continuous data. Differences between groups with those given Tocilizumab versus non-Tocilizumab group were analyzed using Student's $t$-test or the Wilcoxon-Mann-Whitney test (depending on the normality of the data) for continuous variables and using Chi-square $\left(\chi^{\wedge} 2\right)$ or Fisher's exact test for categorical variables. A p-value of $<0.05$ was considered significant.

\section{Results}

Nine hundred thirteen patients were diagnosed with COVID-19 between March 8th 2020-December 31st, 2020. The mean age of the patients diagnosed with COVID-19 was 51.17 ( $\mathrm{SD}=16.66$ ), and $66.5 \%$ of the patients were male. Details of demographics and comorbidities are shown in Table 1. The patient in the Tocilizumab group was older than the non-Tocilizumab group. There was no difference in the morbidity among the group except hypertension which was more prevalent among the Tocilizumab group (Table 1). 93 of the 913 patients received Tocilizumab (10.2\% Tocilizumab group) and 820 of the 913 did not receive Tocilizumab (89.8\% - non-Tocilizumab group). In the nonTocilizumab group, 38 patients (4.6\%) were on mechanical ventilation, In the Tocilizumab group, 40.9\% (38/93) were on mechanical ventilation, whereas $59.1 \%(55 / 93)$ were not on mechanical ventilation. The overall infection rate among the COVID-19 patients was 6\%. Only 4.8\% (39/820) of patients had an infection in the non-Tocilizumab group, whereas $17.2 \%(16 / 93)$ had an infection in the Tocilizumab group $(\mathrm{p}<0.001)$. Infection in patients who had the severe and critical illness in the non-Tocilizumab group was $43 \%$ and $3.5 \%$, respectively, whereas in the Tocilizumab was $47.3 \%$ and $37.6 \%$, respectively, which was statistically significant $(\mathrm{p}<0.001)$. There was no difference in the mortality between patients between the two groups (Table 2). Moreover, no difference in mortality between the groups was observed, even when patients with severe and critical COVID-19 were considered (Table 3 and Figure 1). Of the patients who died, 36.4\% (16/44) received mechanical ventilation and did not receive Tocilizumab, whereas $65.7 \%(23 / 35)$ received both mechanical ventilation and Tocilizumab.

Of the 55 patients that had infections, $47.3 \%$ of patients had one infection, and the remaining had more than one infection. Thirteen patients (23.6\%) had more than four infections. The commonest site of infections was blood (26.4\%) and tracheal aspirate (26.4\%), followed by urine (20.7\%) (Table 4). One hundred forty total infections were reported among the patients; the organisms and percentage among patients who did and did not receive Tocilizumab are shown in Table 5.

\section{Discussion}

Besides the therapeutics, the development of vaccines and emergence of the variant has also posed significant challenges. Results from the trials that evaluated the use of Tocilizumab in treating COVID-19 infection have been inconsistent. ${ }^{28-30}$ Most studies have addressed hospital stay, mechanical ventilation, intensive care unit stay, or 28 days mortality. ${ }^{11,15-17,31-36}$ The increased infection has not been the focus of these studies.

RECOVERY trial presented their findings from the large heterogeneous group. The RECOVERY trial primary outcome from all-cause mortality was $35 \%$ in the usual care group, and $31 \%$ in the Tocilizumab group ( $\mathrm{p}=0.002$ ) compared to our patients where mortality was 8.5 vs $9.7(\mathrm{p}=0.84)$. The infectious complications of Tocilizumab were not studied in the RECOVERY trial. 
Table I Demographics of Patients with COVID-19

\begin{tabular}{|c|c|c|c|c|c|c|c|c|}
\hline \multirow[b]{3}{*}{$\begin{array}{l}\text { Age (Years) (mean } \\
(39))\end{array}$} & & \multirow{2}{*}{\multicolumn{2}{|c|}{ Total $(n=913)$}} & \multicolumn{4}{|c|}{ Tocilizumab } & \multirow{3}{*}{$\begin{array}{l}P \text { value } \\
<0.001\end{array}$} \\
\hline & & & & \multicolumn{2}{|c|}{ No $(n=820)$} & \multicolumn{2}{|c|}{ Yes $(n=93)$} & \\
\hline & & 51.17 & $(16.66)$ & 50.25 & $(16.5 \mid)$ & 59.32 & $(15.80)$ & \\
\hline \multirow[t]{4}{*}{ Age (Years) } & $0-17$ & 21 & $2.3 \%$ & 20 & $2.4 \%$ & I & $1.1 \%$ & \multirow[t]{4}{*}{$<0.001$} \\
\hline & $18-39$ & 218 & $23.9 \%$ & 207 & $25.2 \%$ & 11 & $11.8 \%$ & \\
\hline & $40-69$ & 547 & $59.9 \%$ & 494 & $60.2 \%$ & 53 & $57.0 \%$ & \\
\hline & $>70$ & 127 & $13.9 \%$ & 99 & $12.1 \%$ & 28 & $30.1 \%$ & \\
\hline \multirow[t]{2}{*}{ Gender } & Male & 607 & $66.5 \%$ & 535 & $65.2 \%$ & 72 & $77.4 \%$ & \multirow[t]{2}{*}{0.02} \\
\hline & Female & 306 & $33.5 \%$ & 285 & $34.8 \%$ & 21 & $22.6 \%$ & \\
\hline \multirow[t]{3}{*}{ Race } & African & 738 & $80.8 \%$ & 671 & $81.8 \%$ & 67 & $72.0 \%$ & \multirow[t]{3}{*}{0.06} \\
\hline & Indian & 106 & $11.6 \%$ & 89 & $10.9 \%$ & 17 & $18.3 \%$ & \\
\hline & Others & 69 & $7.6 \%$ & 60 & $7.3 \%$ & 9 & $9.7 \%$ & \\
\hline \multirow{10}{*}{$\begin{array}{l}\text { Baseline } \\
\text { Comorbidities }\end{array}$} & Diabetes & 249 & $27.3 \%$ & 222 & $27.1 \%$ & 27 & $29.0 \%$ & 0.713 \\
\hline & Hypertension & 300 & $32.9 \%$ & 256 & $31.2 \%$ & 44 & $47.3 \%$ & 0.002 \\
\hline & Heart Disease & 48 & $5.3 \%$ & 43 & $5.2 \%$ & 5 & $5.4 \%$ & I \\
\hline & HIV Positive & 21 & $2.3 \%$ & 20 & $2.4 \%$ & I & $1.1 \%$ & 0.714 \\
\hline & COPD & 4 & $0.4 \%$ & 2 & $0.2 \%$ & 2 & $2.2 \%$ & 0.054 \\
\hline & Renal & 37 & $4.1 \%$ & 33 & $4.0 \%$ & 4 & $4.3 \%$ & 0.784 \\
\hline & Cancer & 24 & $2.6 \%$ & 19 & $2.3 \%$ & 5 & $5.4 \%$ & 0.088 \\
\hline & $\begin{array}{l}\text { Rheumatology } \\
\text { Disorders }\end{array}$ & 6 & $0.7 \%$ & 6 & $0.7 \%$ & 0 & $0.0 \%$ & I \\
\hline & Others & 180 & $19.7 \%$ & 159 & $19.4 \%$ & 21 & $22.6 \%$ & 0.492 \\
\hline & None & 408 & $44.7 \%$ & 375 & $45.7 \%$ & 33 & $35.5 \%$ & 0.062 \\
\hline \multirow[t]{3}{*}{ Renal Disease } & Stage 2 & I & $2.7 \%$ & I & $3.0 \%$ & 0 & $0.0 \%$ & \multirow[t]{3}{*}{0.613} \\
\hline & Stage 3 & 7 & $18.9 \%$ & 7 & $21.2 \%$ & 0 & $0.0 \%$ & \\
\hline & Stage 4 & 29 & $78.4 \%$ & 25 & $75.8 \%$ & 4 & $100.0 \%$ & \\
\hline \multirow[t]{3}{*}{ Comorbidities } & None & 409 & $44.8 \%$ & 376 & $45.9 \%$ & 33 & $35.5 \%$ & \multirow[t]{3}{*}{0.152} \\
\hline & I & 252 & $27.6 \%$ & 223 & $27.2 \%$ & 29 & $31.2 \%$ & \\
\hline & $\geq \mathbf{2}$ & 252 & $27.6 \%$ & 221 & $27.0 \%$ & 31 & $33.3 \%$ & \\
\hline Diabetes Overall & & 439 & $48.1 \%$ & 390 & $47.6 \%$ & 49 & $52.7 \%$ & 0.382 \\
\hline $\begin{array}{l}\text { Hypertension } \\
\text { Overall }\end{array}$ & & 344 & $37.7 \%$ & 303 & $37.0 \%$ & 41 & $44.1 \%$ & 0.214 \\
\hline
\end{tabular}

The main concern for using Tocilizumab has been infection, especially among the patients with impaired T-cell immunity such as Tuberculosis, HIV/AIDS, or any immunocompromised status. These patients are usually excluded from these trials. 
Table 2 Infection and Mortality Among Patient with and without Tocilizumab

\begin{tabular}{|c|c|c|c|c|c|c|c|c|}
\hline & $\begin{array}{l}\text { Total COVID-19 } \\
(\mathrm{n}=913)\end{array}$ & Infection & $\begin{array}{l}\text { Infection } \\
\%\end{array}$ & $\begin{array}{l}\text { No-Tocilizumab Group } \\
(n=820)\end{array}$ & $\begin{array}{l}\text { No-Tocilizumab } \\
\text { Group \% }\end{array}$ & $\begin{array}{l}\text { Tocilizumab Group } \\
(\mathrm{n}=93)\end{array}$ & $\begin{array}{l}\text { Tocilizumab } \\
\text { Group \% }\end{array}$ & \\
\hline \multirow{2}{*}{$\begin{array}{l}\text { Bacterial/Fungal } \\
\text { Infection }\end{array}$} & No & 858 & $94.0 \%$ & 781 & $95.2 \%$ & 77 & $82.8 \%$ & \multirow[t]{2}{*}{$<0.001$} \\
\hline & Yes & 55 & $6.0 \%$ & 39 & $4.8 \%$ & 16 & $17.2 \%$ & \\
\hline \multirow{4}{*}{$\begin{array}{l}\text { Final Covid } \\
\text { Severity }\end{array}$} & Mild & 423 & $46.3 \%$ & 409 & $49.9 \%$ & 14 & $15.1 \%$ & \multirow[t]{4}{*}{$<0.001$} \\
\hline & Moderate & 29 & $3.2 \%$ & 29 & $3.5 \%$ & 0 & $0.0 \%$ & \\
\hline & Severe & 397 & $43.5 \%$ & 353 & $43.0 \%$ & 44 & $47.3 \%$ & \\
\hline & Critical & 64 & $7.0 \%$ & 29 & $3.5 \%$ & 35 & $37.6 \%$ & \\
\hline \multirow[t]{2}{*}{ Outcome } & Recovered & 834 & $91.3 \%$ & 750 & $91.5 \%$ & 84 & $90.3 \%$ & \multirow[t]{2}{*}{0.846} \\
\hline & Died & 79 & $8.7 \%$ & 70 & $8.5 \%$ & 9 & $9.7 \%$ & \\
\hline
\end{tabular}


Table 3 Mortality Among Patient with Severe and Critical COVID-19 with and without Tocilizumab

\begin{tabular}{|c|c|c|c|c|c|c|}
\hline \multirow{6}{*}{ SEVERE COVID } & & \multicolumn{4}{|c|}{ Tocilizumab } & \\
\hline & & \multicolumn{2}{|l|}{ No } & \multicolumn{2}{|l|}{ Yes } & \\
\hline & Recovered & 341 & $96.60 \%$ & 40 & $90.90 \%$ & $\mathrm{P}$ value $=0.085$ \\
\hline & Died & 12 & $3.40 \%$ & 4 & $9.10 \%$ & \\
\hline & & \multicolumn{4}{|c|}{ Tocilizumab } & \\
\hline & & \multicolumn{2}{|l|}{ No } & \multicolumn{2}{|l|}{ Yes } & \\
\hline \multirow[t]{2}{*}{ CRITICAL COVID } & Recovered & 5 & $17.20 \%$ & 4 & $11.40 \%$ & $P$ value $=0.720$ \\
\hline & Died & 24 & $82.80 \%$ & 31 & $88.60 \%$ & \\
\hline
\end{tabular}

Secondary infection in a patient receiving the Tocilizumab remains a critical concern in patients who are critically ill and especially receiving the IL-6 inhibitors, which have shown to have increased risk of infection, especially among the critically ill immunocompromised patients. In our study, the patients who received Tocilizumab had a higher risk of infection, which was statistically significant $(\mathrm{p}<0.001)$ when compared to patients who were in the non-Tocilizumab group. This may be because patients in then the Tocilizumab group were more critical and likely were more prone to the superinfection. On the contrary, in a meta-analysis looking at 24 studies with 1156 COVID-19 patients, investigators did not find any significant risk of infections or adverse effects in the Tocilizumab group. ${ }^{20}$ Another trial conducted by WHO showed that secondary infection occurred in $21.9 \%$ of the patients in the IL- 6 group vs $17.6 \%$ in the placebo or nonTocilizumab group, which was not statistically significant (OR 0.99 CI: $0.85-1.16$ ). ${ }^{37}$

Most infections in our patients were from blood, tracheal aspirates, and urine. The commonest infections were gram negatives, Escherichia Coli, Pseudomonas, Enterobacter Cloacae, and Klebsiella pneumonia. Gram-positive and fungal infections were less common. This reflects the pattern of infections seen in hospitals across Africa. Patients who are critically ill and in the ICU likely have a higher rate of infections, but as investigated by Tleyjeh et al, this rate is significantly higher among COVID-19 patients who were treated with the steroids or Tocilizumab. ${ }^{20}$ Our patients have a statistically significantly higher rate of infection among patients receiving the Tocilizumab, which is consistent with the meta-analysis by the Tleyjeh group. ${ }^{20}$ Clinicians need to have a low index of suspicion for superinfection infections in patients who receive Tocilizumab.

\section{Mortality Comparison: Tocilizumab versus Usual Care Group}

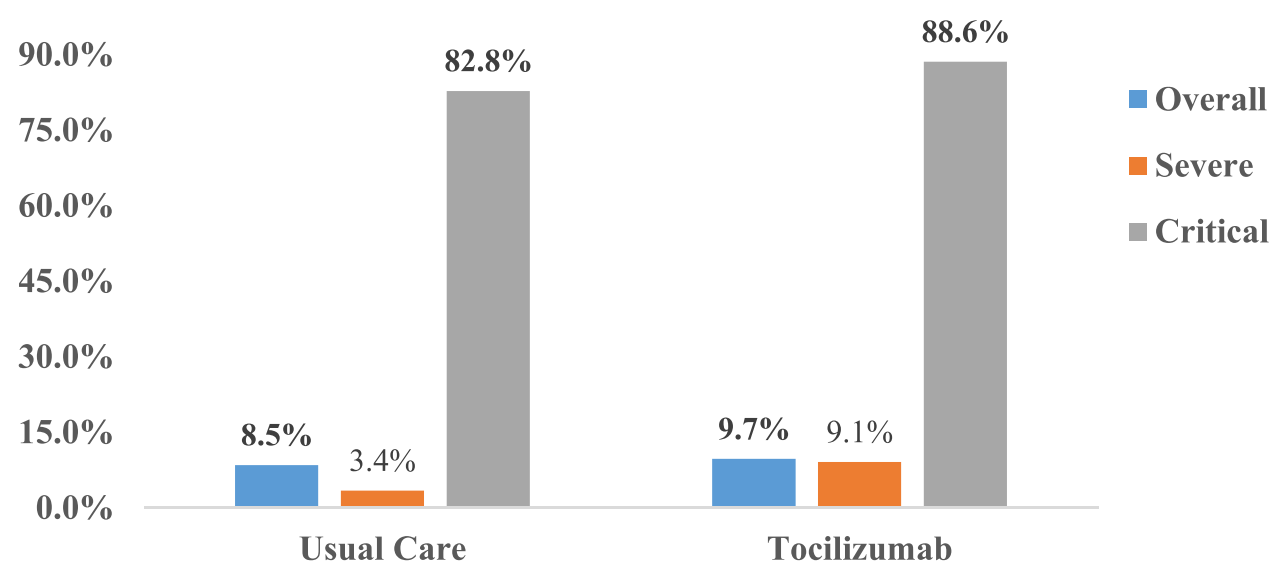

Figure I Mortality Comparison among patients receiving the Tocilizumab versus Usual care group (Overall, Severe COVID-19 and Critical COVID-I9). 
Table 4 Number and Site of Infection Among COVID-19 Patients

\begin{tabular}{|c|c|c|c|}
\hline \multicolumn{4}{|c|}{ Infections from 55 Patients } \\
\hline \multirow[t]{4}{*}{ No of Infections } & 1 & 26 & $47.3 \%$ \\
\hline & 2 & 13 & $23.6 \%$ \\
\hline & 3 & 3 & $5.5 \%$ \\
\hline & $\geq 4$ & 13 & $23.6 \%$ \\
\hline \multirow[t]{10}{*}{ Specimen } & BLOOD & 37 & $26.4 \%$ \\
\hline & $\begin{array}{l}\text { TRACHEAL } \\
\text { ASPIRA }\end{array}$ & 37 & $26.4 \%$ \\
\hline & URINE & 29 & $20.7 \%$ \\
\hline & $\begin{array}{l}\text { BRONCHIAL } \\
\text { ASPIR }\end{array}$ & 10 & $7.1 \%$ \\
\hline & TISSUE & 9 & $6.4 \%$ \\
\hline & SPUTUM & 7 & $5.0 \%$ \\
\hline & WOUND SWAB & 5 & $3.6 \%$ \\
\hline & MISCELLANEOUS & 4 & $2.9 \%$ \\
\hline & CSF & 1 & $0.7 \%$ \\
\hline & PLEURAL FLUID & I & $0.7 \%$ \\
\hline
\end{tabular}

Moreover, the incidence of bloodstream infection (BSI) remains a concern among patients who are critically ill and in ICU. Giacobbe and coworkers studied BSI among critically ill patients with COVID-19. They found the cumulative risk of BSI was $25 \%$ after 15 days and $50 \%$ after 30 days of ICU stay. They also found that anti-inflammatory agents such as steroids and Tocilizumab were associated with an increased risk of BSI with a hazard ratio of $1.07 \mathrm{and} p=0.003 .{ }^{38}$ In our patients, the BSI was $26.4 \%$ which is consistent with other studies.

Interestingly, the prevalence of HIV co-infection was low (2.3\%), despite having a country HIV prevalence of $6 \%$. There was no case of TB superinfection in both the Tocilizumab and non-Tocilizumab groups. This will help alleviate the anxiety of using Tocilizumab in Tuberculosis endemic countries where clinicians worry about having tuberculosis reactivation following Tocilizumab treatment.

The EMPACTA and CONVACTA trial looked at the safety information, including the infections rate. There was a significant difference in the infection rate between those studies and our study. It was $38.3 \%, 5.2 \%$, and $17.2 \%$ in the CONVACATA, EMPACTA and our trial among patients in the Tocilizumab group, whereas $40.6 \%, 7.1 \%$ and $4.8 \%$ in the nonTocilizumab groups. ${ }^{15,16}$ In our trial, the infection rate among the patients taking Tocilizumab was much higher than the nonTocilizumab group (17.2\% vs $4.8 \%)$. As mentioned earlier that patients who received the Tocilizumab were more critical. Moreover, the high cost of the medication may have limited the usage of Tocilizumab in patients who were not critically ill.

There are several limitations of the study: variation in the admission guideline based on the Government regulation in the initial part of the study, small sample size, retrospective study, lack of information on which patients received steroids or anticoagulation therapy, radiological imaging data, variance in the usual care, lower female population, and the option to give the second dose of Tocilizumab based on clinical judgment with few preset parameters rather than the strict guideline. In addition, details regarding the patient's apache score between the Tocilizumab group and the nonTocilizumab group were not available, which could demonstrate differences in mortality and infectious complications. 
Table 5 Organism Incidence Among Patient Receiving Tocilizumab or Not

\begin{tabular}{|c|c|c|c|c|c|c|c|}
\hline \multirow[b]{3}{*}{ Organism } & \multirow[b]{3}{*}{ Esch. coli } & \multirow{2}{*}{\multicolumn{2}{|c|}{ Total $(n=\mid 40)$}} & \multicolumn{4}{|c|}{ Tocilizumab } \\
\hline & & & & \multicolumn{2}{|c|}{ No $(n=89)$} & \multicolumn{2}{|c|}{ Yes $(n=5 I)$} \\
\hline & & 29 & $20.7 \%$ & 17 & $19.1 \%$ & 12 & $23.5 \%$ \\
\hline & Ps. aeruginosa & 18 & $12.9 \%$ & 12 & $13.5 \%$ & 6 & $11.8 \%$ \\
\hline & Ent. cloacae & 13 & $9.3 \%$ & 6 & $6.7 \%$ & 7 & $13.7 \%$ \\
\hline & Aci. baumannii & 11 & $7.9 \%$ & 7 & $7.9 \%$ & 4 & $7.8 \%$ \\
\hline & K. pneumoniae & 11 & $7.9 \%$ & 6 & $6.7 \%$ & 5 & $9.8 \%$ \\
\hline & Staph. aureus & 10 & $7.1 \%$ & 4 & $4.5 \%$ & 6 & $11.8 \%$ \\
\hline & Entero. faecalis & 9 & $6.4 \%$ & 8 & $9.0 \%$ & 1 & $2.0 \%$ \\
\hline & C. auris & 7 & $5.0 \%$ & 5 & $5.6 \%$ & 2 & $3.9 \%$ \\
\hline & C. albicans & 7 & $5.0 \%$ & 5 & $5.6 \%$ & 2 & $3.9 \%$ \\
\hline & C. tropicalis & 5 & $3.6 \%$ & 5 & $5.6 \%$ & 0 & $0.0 \%$ \\
\hline & Staph. epidermidis & 4 & $2.9 \%$ & 3 & $3.4 \%$ & 1 & $2.0 \%$ \\
\hline & C. glabrata & 3 & $2.1 \%$ & 2 & $2.2 \%$ & 1 & $2.0 \%$ \\
\hline & Staph. haemolyticus & 3 & $2.1 \%$ & I & $1.1 \%$ & 2 & $3.9 \%$ \\
\hline & Staph. hominis & 2 & $1.4 \%$ & 2 & $2.2 \%$ & 0 & $0.0 \%$ \\
\hline & C. dubliniensis & I & $0.7 \%$ & I & $1.1 \%$ & 0 & $0.0 \%$ \\
\hline & C. lusitaniae & I & $0.7 \%$ & 0 & $0.0 \%$ & 1 & $2.0 \%$ \\
\hline & C. magnoliae & I & $0.7 \%$ & I & $1.1 \%$ & 0 & $0.0 \%$ \\
\hline & K. oxytoca & I & $0.7 \%$ & I & $1.1 \%$ & 0 & $0.0 \%$ \\
\hline & Ps. fluorescens & I & $0.7 \%$ & I & $1.1 \%$ & 0 & $0.0 \%$ \\
\hline & Salmonella group & I & $0.7 \%$ & I & $1.1 \%$ & 0 & $0.0 \%$ \\
\hline & Staph. warneri & I & $0.7 \%$ & 0 & $0.0 \%$ & 1 & $2.0 \%$ \\
\hline & Str. parasanguinis & I & $0.7 \%$ & I & $1.1 \%$ & 0 & $0.0 \%$ \\
\hline
\end{tabular}

\section{Conclusion}

Tocilizumab was used in a select group of patients who had increasing oxygen requirements and worsening inflammatory markers. This is one of the first studies in Africa comparing infections in patients that received Tocilizumab versus the non-Tocilizumab group. Due to significant variation in the infection rates among the studies, a randomized control trial to assess the safety as it pertains to the superinfection and analysis of multiple superinfections needs to be studied in a diverse and minority population with different COVID-19 severities.

\section{Disclosure}

The authors report no conflicts of interest in this work.

\section{References}

1. Ochani R, Asad A, Yasmin F, et al. COVID-19 pandemic: from origins to outcomes. A comprehensive review of viral pathogenesis, clinical manifestations, diagnostic evaluation, and management. Infez Med. 2021;29(1):20-36. 
2. Sharma M, Surani S. Revisiting one of the dreaded outcomes of the current pandemic: pulmonary embolism in COVID-19. Medicina. 2020;56(12). doi:10.3390/medicina56120670

3. Corona Virus Update Worldometer: John Hopkins; 2021. Available from: https://www.worldometers.info/coronavirus/. Accessed February 22, 2022.

4. Malekzadeh R, Abedini A, Mohsenpour B, et al. Subcutaneous tocilizumab in adults with severe and critical COVID-19: a prospective open-label uncontrolled multicenter trial. Int Immunopharmacol. 2020;89(Pt B):107102. doi:10.1016/j.intimp.2020.107102

5. Le RQ, Li L, Yuan W, et al. FDA approval summary: tocilizumab for treatment of chimeric antigen receptor t cell-induced severe or life-threatening cytokine release syndrome. Oncologist. 2018;23(8):943-947. doi:10.1634/theoncologist.2018-0028

6. Tanaka T, Ogata A, Narazaki M. Tocilizumab for the treatment of rheumatoid arthritis. Expert Rev Clin Immunol. 2010;6(6):843-854. doi:10.1586/ eci. 10.70

7. Schirmer M, Muratore F, Salvarani C. Tocilizumab for the treatment of giant cell arteritis. Expert Rev Clin Immunol. 2018;14(5):339-349. doi:10.1080/1744666X.2018.1468251

8. Brunner HI, Ruperto N, Zuber Z, et al. Efficacy and safety of Tocilizumab in patients with polyarticular-course juvenile idiopathic arthritis: results from a Phase 3, randomised, double-blind withdrawal trial. Ann Rheum Dis. 2015;74(6):1110-1117. doi:10.1136/annrheumdis-2014-205351

9. Rosa K. Tocilizumab: oncLive; 2021. Available from: https:/www.onclive.com/view/fda-grants-emergency-use-authorization-to-tocilizumab-forcovid-19. Accessed February 22, 2022.

10. Sebba A. Tocilizumab: the first interleukin-6-receptor inhibitor. Am J Health Syst Pharm. 2008;65(15):1413-1418. doi:10.2146/ajhp070449

11. Abaleke E, Abbas M, Abbasi S, et al. Tocilizumab in patients admitted to hospital with COVID-19 (RECOVERY): a randomised, controlled, open-label, platform trial. Lancet. 2021;397(10285):1637-1645.

12. Alam W, Bizri AR. Efficacy of Tocilizumab in COVID-19: a review of the current evidence. Sci Prog. 2021;104(3):368504211030372. doi: $10.1177 / 00368504211030372$

13. Cellina M, Orsi M, Bombaci F, Sala M, Marino P, Oliva G. Favorable changes of CT findings in a patient with COVID-19 pneumonia after treatment with Tocilizumab. Diagn Interv Imaging. 2020;101(5):323-324. doi:10.1016/j.diii.2020.03.010

14. Stone JH, Frigault MJ, Serling-Boyd NJ, et al. Efficacy of tocilizumab in patients hospitalized with Covid-19. N Engl J Med. 2020;383 (24):2333-2344. doi:10.1056/NEJMoa2028836

15. Salama C, Han J, Yau L, et al. Tocilizumab in patients hospitalized with Covid-19 pneumonia. N Engl J Med. 2021;384(1):20-30. doi:10.1056/ NEJMoa2030340

16. Rosas IO, Brau N, Waters M, et al. Tocilizumab in hospitalized patients with severe Covid-19 pneumonia. $N$ Engl J Med. 2021;384(16):1503-1516. doi:10.1056/NEJMoa2028700

17. Roche provides update on the Phase III REMDACTA trial of Actemra/RoActemra plus Veklury in patients with severe COVID-19 pneumonia: roche; 2021. Available from: https://www.roche.com/media/releases/med-cor-2021-03-11.htm. Accessed February $22,2022$.

18. Edwards CJ. IL-6 inhibition and infection: treating patients with Tocilizumab. Rheumatology. 2012;51(5):769-770. doi:10.1093/rheumatology/ ker311

19. Pettit NN, Nguyen CT, Mutlu GM, et al. Late onset infectious complications and safety of Tocilizumab in the management of COVID-19. J Med Virol. 2021;93(3):1459-1464. doi:10.1002/jmv.26429

20. Tleyjeh IM, Kashour Z, Riaz M, Hassett L, Veiga VC, Kashour T. Efficacy and safety of Tocilizumab in COVID-19 patients: a living systematic review and meta-analysis, first update. Clin Microbiol Infect. 2021;27(8):1076-1082. doi:10.1016/j.cmi.2021.04.019

21. Campochiaro C, Della-Torre E, Cavalli G, et al. Efficacy and safety of Tocilizumab in severe COVID-19 patients: a single-centre retrospective cohort study. Eur J Intern Med. 2020;76:43-49. doi:10.1016/j.ejim.2020.05.021

22. Cellina M, Fetoni V, Baron P, Orsi M, Oliva G. Listeria meningoencephalitis in a patient with rheumatoid arthritis on anti-interleukin 6 receptor antibody tocilizumab. J Clin Rheumatol. 2015;21(6):330. doi:10.1097/RHU.0000000000000287

23. Enos M, Sitienei J, Ong'ang'o J, et al. Kenya tuberculosis prevalence survey 2016: challenges and opportunities of ending TB in Kenya. PLoS One. 2018;13(12):e0209098. doi:10.1371/journal.pone.0209098

24. Carroll KC, Pfaller MA, Landry ML, et al. Manual of Clinical Microbiology. 12th ed. Washington, DC: ASM press; 2019.

25. Institure CaLS. CLSI M100, ED 31, 2021 performance standards for antimicrobial susceptibility testing; 2021. Available from: https://clsi.org/ about/press-releases/clsi-publishes-m100-performance-standards-for-antimicrobial-susceptibility-testing-31st-edition/. Accessed February $22,2022$.

26. Procop GDP, Fuller J, Hanson K, et al. CLSI M60 ED2, 2020 performance standards for antifungal susceptibility testing of yeast.: clinical laboratory standard institute; 2020. Available from: https://clsi.org/media/3680/m60ed2_sample.pdf. Accessed February 22, 2022.

27. Harris PA, Taylor R, Minor BL, et al. The REDCap consortium: building an international community of software platform partners. $J$ Biomed Inform. 2019;95:103208. doi:10.1016/j.jbi.2019.103208

28. Abdalla M, El-Arabey AA, Jiang X. What are the challenges faced by COVID-19 vaccines? Expert Rev Vaccines. 2022;21(1):5-7. doi:10.1080/ 14760584.2022 .2008245

29. El-Arabey AA, Abdalla M. In the face of the future, what do we learn from COVID-19? Hum Vaccin Immunother. 2021;17(11):4119-4120. doi:10.1080/21645515.2021.1963174

30. Abdalla M, El-Arabey AA, Jiang X. Are the new SARS-CoV-2 variants resistant against the vaccine? Hum Vaccin Immunother. 2021;17 (10):3489-3490. doi:10.1080/21645515.2021.1925503

31. Klopfenstein T, Zayet S, Lohse A, et al. Tocilizumab therapy reduced intensive care unit admissions and/or mortality in COVID-19 patients. Med Mal Infect. 2020;50(5):397-400. doi:10.1016/j.medmal.2020.05.001

32. Alzghari SK, Acuna VS. Supportive treatment with Tocilizumab for COVID-19: a Systematic review. J Clin Virol. 2020;127:104380. doi:10.1016/j. jev.2020.104380

33. Zhang C, Wu Z, Li JW, Zhao H, Wang GQ. Cytokine release syndrome in severe COVID-19: interleukin-6 receptor antagonist tocilizumab may be the key to reduce mortality. Int J Antimicrob Agents. 2020;55(5):105954. doi:10.1016/j.ijantimicag.2020.105954

34. Cortegiani A, Ippolito M, Einav S. Rationale and evidence on the use of tocilizumab in COVID-19: a systematic review authors' reply. Pulmonology. 2021;27(1):87-88. doi:10.1016/j.pulmoe.2020.10.003

35. Mikulska M, Nicolini LA, Signori A, et al. Tocilizumab and steroid treatment in patients with COVID-19 pneumonia. PLoS One. 2020;15(8): e0237831. doi:10.1371/journal.pone.0237831 
36. Lan SH, Lai CC, Huang HT, Chang SP, Lu LC, Hsueh PR. Tocilizumab for severe COVID-19: a systematic review and meta-analysis. Int J Antimicrob Agents. 2020;56(3):106103. doi:10.1016/j.ijantimicag.2020.106103

37. Group TWREAfC-TRW. Association between administration of IL-6 antagonists and mortality among patients hospitalized for COVID-19 A meta-analysis. JAMA. 2021;326(6):499-518. doi:10.1001/jama.2021.11330

38. Giacobbe DR, Battaglini D, Ball L, et al. Bloodstream infections in critically ill patients with COVID-19. Eur J Clin Invest. 2020;50(10):e13319. doi:10.1111/eci.13319

\section{Publish your work in this journal}

The International Journal of General Medicine is an international, peer-reviewed open-access journal that focuses on general and internal medicine, pathogenesis, epidemiology, diagnosis, monitoring and treatment protocols. The journal is characterized by the rapid reporting of reviews, original research and clinical studies across all disease areas. The manuscript management system is completely online and includes a very quick and fair peer-review system, which is all easy to use. Visit http://www.dovepress.com/testimonials.php to read real quotes from published authors.

Submit your manuscript here: https://www.dovepress.com/international-journal-of-general-medicine-journal 